\title{
Guidelines, Standards and Best Practice for Seismic Hazard Assessment and Rockburst Risk Management in South African Mines
}

\section{R.J. Durrheim CSIR Natural Resources and the Environment and University of Witwatersrand, South Africa}

A. Cichowicz Council for Geoscience, South Africa

R. Ebrahim-Trollope Geohydroseis CC, South Africa

F. Essrich SiM Mining Consultants Pty Ltd, South Africa

O. Goldbach CSIR Natural Resources and the Environment, South Africa

L.M. Linzer CSIR Natural Resources and the Environment, South Africa

S.M. Spottiswoode CSIR Natural Resources and the Environment, South Africa

T. Stankiewicz Hamerkop Scientific Services, South Africa

\begin{abstract}
Seismic monitoring, analysis and interpretation are key components of the hazard assessment and risk management system on rockburst-prone mines. The Mine Health and Safety Council commissioned a task as part of the project "Minimising the rockburst risk" (SIM050302) to review current practice on South African mines and to formulate standards, guidelines, and descriptions of best practice. Standards were set for some areas of mine seismology practice such as network design and emergency response. In other areas of practice, such as data processing, it was only possible to provide guidelines. In yet other areas of practice, such as seismic hazard assessment and risk management, most methods currently in use have not been rigorously evaluated and validated. Many methods rely, to a greater or lesser extent, on local experience and subjective judgement. Tacit knowledge still has to be translated into explicit guidelines and procedures. It is thus deemed premature to set standards, or even firm guidelines. Current practice is described, and methods to evaluate the procedures are proposed.
\end{abstract}

\section{Introduction}

Rockbursts are a major risk of deep and high-stress mining in South Africa, causing damage to infrastructure, loss of production, and injury and death to mine workers. Although there has been an encouraging improvement in safety statistics in recent years, particularly in the gold sector, rockbursting is likely to remain a significant risk for the foreseeable future. The depths of gold and platinum mines are destined to increase, and it is probable that an increasing proportion of production will be derived from remnants, where the risk of rockbursting has historically been high. At the Mine Health and Safety Summit held in 2003, employers, labour and government agreed to work together to reduce fatalities by 20 per cent per annum in an effort to meet international benchmarks by 2013. However, at the Mine Health and Safety Summit held on 7 June 2007, the Chamber of Mines president Lazarus Zim reported that the South African mining industry had failed to reach its target of $20 \%$ improvement in 2006 . The gold mining sector had suffered 113 fatalities, and the fatality frequency rate had worsened by 10\% (Mining Weekly on-line, 8 June 2007). It is thus critical that the South African mining industry continues to strive to reduce the risk posed by rockbursts, and that appropriate research and development is conducted to support this effort.

The Mine Health and Safety Act (Act 29 of 1996) seeks to establish a culture of health and safety in the mining industry, and stipulates that owners and managers should take "reasonable measures" to ensure that the working environment is healthy and safe when a mine is designed, constructed, equipped, operated and decommissioned. Section 11 of the Act requires managers to identify hazards and assess risks, and to implement measures to eliminate, control and minimise the identified risks. Section 9 requires managers to prepare and implement codes of practice in accordance with the guidelines issued by the Chief Inspector. 
Seismic monitoring systems and analysis and interpretation procedures are key components of the risk management system on rockburst-prone mines. The Mine Health and Safety Council commissioned a task as part of the project "Minimising the rockburst risk" (SIM050302) to review current practice on South African mines and to formulate standards, guidelines, and descriptions of best practice. These are intended to:

- Assist providers of mine seismology technologies and services to improve the quality of monitoring and analysis.

- Help rock engineering practitioners to respond appropriately to seismic information.

- Assist the mining inspectorate to improve the effectiveness of regulation and enforcement.

- Provide mine owners and managers with an updated review of technology and practice, which can be used to develop strategies and operating procedures that will minimise rockburst losses and meet both the letter and spirit of the Mine Health and Safety Act.

\section{Project methodology}

The following principles were used when formulating standards, guidelines and procedures:

- They should be "reasonably practicable"; taking into account the age, expected life span, and the level of seismicity experienced by a particular mine.

- They should support a programme of continuous improvement. Measurable criteria or standards should be defined that can be used to audit performance, track improvement, and enable systems and performance to be benchmarked against other operations.

Chapters 8 and 9 of “A Handbook on Rock Engineering Practice for Tabular Hard Rock Mines” (Jager and Ryder, 1999) entitled "Rockbursting" (Durrheim, 1999), and "A guide to routine seismic monitoring in mines” (Mendecki et al., 1999), respectively, were taken as the starting point. The study seeks to update and expand these chapters by: including recent advances in technology and changes in mining practice, drawing on the experience and knowledge of a larger community of practitioners, describing procedures and standards in greater detail, and describing instances of best practice.

Several codes of practice to combat rockfall and rockburst accidents, drawn up by mines in accordance with Sections 9(2) and (3) of the Mine Health and Safety Act (Act 29 of 1996) and the relevant guidelines (DME, 2002), were reviewed. A survey of current practice was undertaken through structured interviews with rock engineering practitioners, senior production personnel, and providers of seismic monitoring services. The survey covered both gold and platinum mines, the various mining districts, and a range of companies. The team members jointly assessed the reliability and usefulness of current practices. Considerable variation in practice was found, which is not surprising as the operations differ considerably with respect to the geotechnical areas, mining methods, level of seismicity, age of mine, and expected life of mine. The final report (Durrheim et al., 2007) was delivered to the Mine Health and Safety Council in May 2007 for review by the Rock Engineering Technical Advisory Committee.

\section{Seismic monitoring objectives}

Seismic monitoring objectives are determined by the conditions that prevail on a particular mine, the potential seismic hazard(s) posed by these conditions, the mine's strategy to mitigate the hazards, the Mine Health and Safety Act (Act 29 of 1996), and the guideline for the code of practice to combat rockfall and rockburst accidents (DME, 2002). The primary objectives of seismic monitoring in rockburst-prone mines are:

- Rapid response to rockbursts to limit the loss of life and any further damage by directing rescue teams to those areas likely to have been affected and by halting hoisting until the shaft infrastructure has been examined.

- Seismic hazard assessments (SHA) to guide efforts to mitigate the risks associated with rockbursts. To synchronise SHA with typical mining cycles, SHA procedures are routinely described as long, medium, and short term, with time spans of years, months, and days to minutes, respectively. While 
it is generally agreed that accurate rockburst prediction (when, where, how big will the next event be?) is a difficult and distant goal, the project team believes that effective short-term hazard assessment is desirable and achievable. In the report the "state of the art" with respect to SHA is described, with the immediate acknowledgement that it does not yet meet the requirements of mine operators and workers.

- Back analysis of large and/or damaging seismic events, whether associated with accidents or not, in order to determine the cause of the event(s) and to explain the severity and distribution of damage. This understanding is essential for developing strategies to minimise seismic hazard and rockburst risk.

- Research and experimental development to improve knowledge of the rockbursting phenomena and technologies to mitigate the hazard.

It is recommended that each mine should establish its current and future seismic monitoring objectives so that networks are designed appropriately, and suitable data processing, analysis and interpretation procedures and services are implemented. The seismic monitoring objectives should be reviewed annually and recorded in the mine's code of practice.

\section{Network design}

\subsection{Performance criteria}

The primary output of seismic monitoring in mines is the time and location of seismic events. No other objective can be met if the seismic network fails to produce this. However, the monitoring objectives may differ for various parts of the mine and may change with time as some areas are mined out and new stopes established. Performance criteria for seismic networks are presented in Table 1.

Table 1 Suggested performance criteria for mine seismic networks

\begin{tabular}{|c|c|c|c|}
\hline Monitoring objective & $\begin{array}{c}\text { Sensitivity } \\
\left(\mathbf{M}_{\min }\right)\end{array}$ & $\begin{array}{l}\text { Location accuracy } \\
\text { (in plan) }\end{array}$ & $\begin{array}{c}\text { Processing } \\
\text { speed }\end{array}$ \\
\hline Rapid response to potential rockbursts & 0.5 & $200 \mathrm{~m}$ & 2 minutes \\
\hline Long-term SHA* & 1.0 & $200 \mathrm{~m}$ & days \\
\hline Medium-term SHA* & 0.0 & $30 \mathrm{~m}$ & days \\
\hline Short-term SHA* & -1.0 & $30 \mathrm{~m}$ & 10 minutes \\
\hline $\begin{array}{l}\text { Emergency alarm (experimental systems under } \\
\text { development) }\end{array}$ & -3.0 & $30 \mathrm{~m}$ & seconds \\
\hline $\begin{array}{l}\text { Back analysis of large events (sufficient sensitivity } \\
\text { to detect aftershocks) }\end{array}$ & 0.0 & $30 \mathrm{~m}$ & hours \\
\hline Regional monitoring & 1.0 & $200 \mathrm{~m}$ & 10 minutes \\
\hline
\end{tabular}

The geometric configuration of the sensors is the primary factor that determines the sensitivity and location accuracy of a network. Generally, the location accuracy and sensitivity improve with an increased density of sensor sites. A common standard is that an event should be located using at least five tri-axial sites or 15 valid seismograms. When designing the network, long-term mine plans should be taken into account. The effect on network performance should any sensor fail should also be considered. New sensor sites should be installed routinely as the mine expands. Data acquisition units may be relocated from sites in areas where mining activity has terminated. 


\subsection{System specifications}

The seismic monitoring objectives can only be met if a seismic network is designed appropriately. However, there are inevitable tradeoffs between cost and performance, and monitoring objectives may vary for different parts of the mine e.g. back areas, active mining sections, and the shaft pillar. Guidelines for the design of seismic networks are presented in Table 2.

Table 2 Guidelines for the design of seismic networks

\begin{tabular}{|c|c|c|}
\hline & \multicolumn{2}{|c|}{ Recommended minimum system characteristics } \\
\hline \multirow{4}{*}{$\begin{array}{r}\text { Scale } \\
\text { Sensitivity }\end{array}$} & Mine-wide & Research/special areas \\
\hline & $300 \mathrm{~m}-5 \mathrm{~km}$ & $100 \mathrm{~m}-1 \mathrm{~km}$ \\
\hline & $\mathbf{M}_{\min }=0$ for back areas & $M_{\min }=-2$ \\
\hline & $M_{\min }=-1$ for active mining areas & \\
\hline \multicolumn{3}{|l|}{ Parameters } \\
\hline \multirow{2}{*}{ Sampling rate } & $1 \mathrm{kHz}$ for back areas & $10 \mathrm{kHz}$ \\
\hline & $2 \mathrm{kHz}$ for active mining areas & \\
\hline Sensor density & 5 sites within $1 \mathrm{~km}$ of source & 5 sites within $300 \mathrm{~m}$ of source \\
\hline Sensors & $\begin{array}{l}\text { Triaxial sets of geophones or } \\
\text { accelerometers (e.g. SM-6 } 4.5 \mathrm{~Hz} \\
\text { geophones). }\end{array}$ & Accelerometers \\
\hline Dynamic range & $120 \mathrm{~dB}$ & $110 \mathrm{~dB}$ \\
\hline Resolution at all levels & 10 bits & 10 bits \\
\hline Event rate & 1-1000 events/day & 1000-10 000 events/day \\
\hline Sustained event rate & 250 per hour & 2500 per hour \\
\hline Communication rate & $9.6 \mathrm{~kb} / \mathrm{s}$ & $115 \mathrm{~kb} / \mathrm{s}$ \\
\hline Communication method & Dual twisted pair or optical fibre & Coaxial copper cable or optical fibre \\
\hline Timing & GPS & GPS \\
\hline
\end{tabular}

The guidelines in Table 2 are similar to those proposed by Mendecki et al. (1999: 307, Table 9.7.1). The most important amendments are:

- The "regional mining" category is no longer applicable as all rockburst-prone mines now operate their own mine-wide networks. However, "virtual super-networks" will most likely be created in the future by combining data from adjacent mine-wide networks. This will improve estimates of the source parameters of events that are "ahead of mining" i.e. external to one mine network, but located between two adjacent networks.

- Piezoelectric accelerometers have certain advantages compared to geophones: they are comparatively insensitive to low frequencies and so can record larger events without clipping; and are sensitive to higher frequencies so are suitable for dense networks designed to detect very small events. However, combinations of accelerometers and geophones were found to be problematic as the source parameters calculated using the different types of sensors were inconsistent. Consequently, accelerometers are rarely used in mine-wide networks in South Africa. Where accelerometers are present, the accelerograms are generally only used to pick arrival times and not to calculate source parameters. However, seismic systems elsewhere have used accelerometers successfully (e.g. Trifu, 2001), and it is believed that useful data can be obtained if good quality accelerometers are installed. Perhaps more work is needed to prove the value of accelerometers in mine networks. 
- High sensitivity networks $\left(\mathrm{M}_{\min }=-2\right.$ or even $\left.\mathrm{M}_{\min }=-3\right)$ have not been found to be any more useful in detecting precursors to large seismic events than standard mine-wide networks $\left(M_{\min }=-1\right)$, although G. van Aswegen (ISSI, pers. comm., 2007) suggested that changes to the mining layout may have negated the experimental design of some of these studies. The determination of source parameters for the large number of events recorded can be very time-consuming if it is done manually. Nevertheless microseismic networks are included here as it is considered possible that they will be found to be useful for monitoring special areas such as remnants, as well as for research work. It is believed that there is scope to improve the automatic processing of large numbers of events through the development of better diagnostic procedures to identify and exclude noisy data from analysis, and better automatic processing algorithms.

\section{Network operation}

\subsection{Calibration}

The P- and S-wave velocities are generally assumed to be constant for a mine network. However, an error of $3 \%$ in the velocity translates to an error of $30 \mathrm{~m}$ for a typical source-sensor ray path of $1000 \mathrm{~m}$. This is an order of magnitude greater than the typical error contributed by inaccuracies in pick times or low sampling rate. Factors that affect the accuracy of the velocity model include the geological structure, the presence of mining excavations, stress variations and fracturing.

The estimation of P- and S-wave velocities is fundamental to reducing location errors. Calibration blasts are commonly used to do this: if the distance between the blast and the sensor site is known, the measured travel-time can be used to calculate the wave velocities, which may then be used in the location algorithm. It is recommended that calibration blasts should be detonated at several dispersed locations to perform a crude survey of the seismic velocities. If the velocity variations exceed 3\%, it is recommended that this be taken into account in the event location procedures. The procedure may simply involve excluding data recorded at certain sensor sites from the calculation, or it may entail the development of a more detailed velocity model. Spottiswoode and Linzer (2005) have shown that seismic recordings of development blasts can be used for improving seismic locations.

The methods used to calculate magnitude by South African mine seismic networks were found to be inconsistent: in some instances, magnitudes were based on energy, in others on the seismic moment, and in yet other cases a combination of energy and moment was used. It is recommended that the methods used to calculate local magnitude should be standardised and calibrated with the South African Seismological network (SANSN), and that the Council for Geoscience should expand its network to include at least one site in each of the mining regions.

\subsection{Performance monitoring}

"What gets measured, gets done" is a precept that applies as much to the management of a seismic network as to any other management function. The network and site efficiencies should be tracked. Furthermore, a log should be kept of all emergency response notifications, containing information such as the fast and final location, the person(s) notified, the time of the notification, and the actions taken.

A power failure may disable an entire seismic network. Power failures are sometimes caused by large seismic events, resulting in the loss of critical data. It is recommended that mines take measures to prevent the loss of data, e.g. by installing uninterruptible power supply units.

A sensor site may be disabled by a power failure, break in the data transmission line, or failure of electronic components. These faults may have many causes, ranging from fires and falls of ground, to power surges and cable theft. The loss of a sensor site could have a serious effect on the accuracy of locations. Every effort should be made to restore such sites as quickly as possible. As some sites are more crucial than others (e.g. a site close to working place that has a high level of seismicity is generally more important than a site in the back area), an assessment of the loss of sensitivity and location accuracy due to the disabled site should be made. Any crucial site should be repaired or replaced immediately. 
A tri-axial sensor may operate with one or two disabled geophones/accelerometers. The remaining transducer(s) may be useful for source location, although the determination of other source parameters may be compromised. These sensors should be repaired and/or replaced as part of the normal maintenance schedule. It is desirable that at least $80 \%$ of the sites should have all three transducers functional.

\subsection{Management issues}

The maintenance of a mine-wide seismic network to produce data of a consistently high quality poses significant challenges. During the last decade there have been significant changes in the way the seismic monitoring service is provided, as many mining companies have chosen to outsource some or all parts of the operation. Many mines have changed hands in the last decade, which has sometimes led to gaps in monitoring and loss of databases.

Consistency in the methods and parameters used to calculate source parameters is especially important when performing seismic hazard assessments, or processing artefacts may mask trends in the data. New versions of processing software and parameters are implemented from time to time to incorporate advances in theory and technology, or to fix bugs. It may be necessary to recalculate the source parameters of all events in the seismic database. Sometimes it may not be clear if the parameters of all events were previously recalculated, and a consistency check has to be performed. Considering the significant resources expended on acquiring seismic data and the potential benefits that can be derived from a complete data set, standard operating procedures for data backups should be formulated.

\section{Estimation of seismic source parameters}

\subsection{Location}

As a rule of thumb, it should be possible to reduce the location error to $3 \%$ of the average hypocentre-site distance if high quality data from at least five sites of reasonable configuration is used. The easiest way to improve the accuracy of locations would thus seem to be to increase the density of sensor sites. Unfortunately, the installation of additional sensor sites is an expensive option. Sophisticated mathematical methods, such as joint hypocentral determination, may also be used to improve accuracy (Cichowicz et al., 2005).

\subsection{Quantification of source parameters and mechanisms}

Accurate description of the seismic source is considered vital for meaningful back analysis, and for the development of effective seismic hazard assessment methods. The fundamental source parameters of a seismic event are its time, location, energy and scalar moment, from which many other parameters may be derived. For example:

- Stress change associated with the event (stress drop and apparent stress).

- Dimensions of the source (radius, area or volume).

- Slip on the fault (displacement and velocity of slip, the orientation of the slip vector).

- Descriptions of the source mechanism (Energy Index, Es/Ep, and the components of the moment tensor). Moment tensor solutions are often unreliable owing to the planarity of many mine networks.

Source parameter calculations are affected by the same factors as location calculations (see section 4.1), and several additional factors such as the frequency range of the recording instrumentation, and the material and mechanical properties of the medium (e.g. density, Young's and shear moduli, attenuation and scattering). Complex ray paths caused by fracturing and extreme stress variations around deep-level stope are a particular concern. Evidence of the negative effects of mining excavations on source parameters is the fact that displacement seismograms generally do not show the uni-directional P- and S-wave pulses that are expected from theory. Furthermore, simplifying assumptions are made regarding the source model (e.g. the Brune (1970) model assumes that the rupture resembles a "penny-shaped crack"), and many of the mathematical techniques that are used during data processing and analysis require intelligent choice of parameters (e.g. Fourier analysis, digital filtering, curve fitting). It has been found that pillar-burst events 
produce simple seismograms that do not fit the current theories at all (Spottiswoode et al., 2006). These are areas of active research, and it was beyond the scope of this investigation to study and compare these steps and parameters in detail.

\section{Procedures}

Fuller descriptions of procedures and examples may be found in Durrheim et al. (2007).

\subsection{Emergency response to rockbursts}

The primary objective of seismic monitoring in rockburst-prone mines is to limit the loss of life and/or damage to shaft infrastructure following a seismic event. This is achieved through (i) the rapid identification of areas that may have suffered damage so that rescue efforts may be initiated as quickly as possible; and (ii) the halting of hoisting operations, should damage to the shaft barrel or steelwork be suspected. This procedure can be broken down into several steps:

- Determination of notification thresholds. In order to decide whether the seismic processors should notify the mine control room that potential damage has occurred, information should be gathered so that thresholds can be defined. A comprehensive rockburst database should be compiled, and the relationship between the event magnitude, the distance of the source from the working place, and intensity of rockburst damage should be investigated. A threshold should be selected that ensures that a notification is issued for, say, 95\% of the cases where damage that poses a risk to safety is experienced. Differences between emission sources (face bursts, fault slip, etc) and areas of the mine (stopes, tunnels, shafts) should be taken into account. Typical notification thresholds are $\mathrm{M}_{\mathrm{L}}=1$ during day shift and $\mathrm{M}_{\mathrm{L}}=2$ during afternoon and night shift. On mines prone to face bursts, the notification threshold may be reduced to $\mathrm{M}_{\mathrm{L}}=0.5$ for on-shift events close to the face.

- Quick location of potential areas of rockburst damage. The working places closest to the hypocentre of the seismic event must be identified as quickly as possible. This requires that the seismic event should be located with an accuracy of $200 \mathrm{~m}$ or better in plan, and that the hypocentral coordinates can easily be used to identify the names and/or numbers of nearby working places. The severity of rockburst damage is dependent on many factors in addition to the distance from the seismic event. Thus it is more important to identify quickly the area in which damage could possibly have occurred, rather than to conduct detailed seismogram analysis to identify the panel closest to the hypocentre.

- Rapid notification of the control room. In order to enable medical attention to be given within the "golden hour", the location of the event and a list of the working places most likely to have sustained damage should be transmitted to the mine control room within a few minutes. The communication of notices may be quite a complicated process, depending on a host of mine-specific factors. It is standard practice for the seismic processing centre to inform mine control rooms and designated personnel of potentially damaging events using media such as email, telephone calls or SMS.

\subsection{Long-term SHA}

Long-term SHA supports annual and longer-term mine planning. A well-maintained seismic database allows hazardous geological structures and mine layouts to be recognised, and can also be used to calibrate numerical models so that standard rock engineering design tools can be applied appropriately. In new mining areas, data from geologically similar areas may be used for model calibration. Long-term seismic hazard trends may be used to determine the effectiveness of the mining strategies that have previously been applied.

\subsection{Medium-term SHA}

Most mines review production and planning on a monthly basis. Medium-term SHA is a key input to the monthly planning meetings, enabling mining strategies to be developed that will minimise the seismic hazard and exposure. Seismicity is the quantitative description of the space, time and magnitude distribution of seismic events occurring within a given volume $\Delta \mathrm{V}$ in a time interval $\Delta \mathrm{t}$. Seismicity can be quantified using the following four largely independent quantities: average time between consecutive events; average distance between consecutive events; sum of seismic moments, $\Sigma \mathrm{M}$; and sum of radiated energies, $\Sigma \mathrm{E}$. Many 
parameters can be derived from the basic quantities to describe the statistical properties of co-seismic deformation and the associated changes in stress, strain and rheology. Appropriate seismic analyses allow the relationship between seismic hazard and mining layouts, mining rates and local geological features to be established and monitored. Appropriate actions can then be taken to mitigate the rockburst risk. Mediumterm SHA can be broken down into several steps:

- Determine the required sensitivity and location accuracy. The parameters set for short-term SHA will normally be adequate.

- Delimit datasets in space and time. This is not a simple matter, as there is an inevitable trade-off between statistical significance and resolution: the larger the area considered and the longer the time window, the greater the number of events analysed and the greater the statistical stability, but the poorer the resolution in space and time. Furthermore, the locus of seismic events migrates as mining progresses, and the effective sensitivity and location accuracy of the network changes accordingly. Lastly, the rate of mining may vary from month to month, complicating the comparison.

- Select the seismic parameters to be analysed. Several case studies have been published that demonstrate the utility of medium-term SHA (e.g. Spottiswoode, 2005; Van Aswegen, 2003 and 2005). However, no general procedure for medium-term SHA has emerged. Practice is largely based on experience and local knowledge, and varies considerably between mines and even between different areas on a single mine.

- Select the non-seismic parameters to be analysed. Many mines have implemented in-house customised rockburst/rockfall hazard assessment systems that incorporate geotechnical and mining parameters e.g. proximity of geological structures, face shape, lead-lag distances, ground conditions, compliance with support standards, and the outputs of numerical modelling such as Energy Release Rate (ERR) and Excess Shear Stress (ESS) (Jager and Ryder, 1999). At the time of writing the report there was considerable variation in the parameters used. Some mines (e.g. Impala and AngloGold Ashanti) emphasised underground observations by teams of strata control officers and observers, while other mining companies (e.g. Harmony) relied largely on information derived from mine plans. Current practice is to gather these data monthly, at best. There was no objective information that allowed the merits of the approaches to be compared. Spottiswoode et al. (2007) have performed extensive comparisons between seismicity and modelling. They have shown that the rate of seismicity is proportional to strain energy release and that this proportionality is improved when unmined ground is considered to fail at a normal stress of $250 \mathrm{MPa}$.

- Identify signals that might indicate a change in seismic hazard. A variety of methodologies have been implemented, including spatial analysis, clustering, $\Sigma \mathrm{E}-\Sigma \mathrm{M}$ diagrams, stiffness diagrams, seismic response parameter, time-of-day distribution, and integrated methods.

While considerable experience in medium-term SHA has been gained since Mendecki et al. (1999) wrote "A guide to routine monitoring in mines", few papers or technical reports have been published that describe the procedures in sufficient detail to allow replication, or that evaluate the results with sufficient rigour to enable a reader to judge which procedures are the most promising. Thus it is considered premature to define standards and guidelines. It is recommended that procedures are documented and rigorously tested in future.

\subsection{Short-term SHA}

Short-term SHA can be broken down into several steps:

- Determine of the required sensitivity and location accuracy.

- Delimit datasets in space and time.

- Select the seismic parameters to be analysed. Parameters commonly used include seismic strain and strain rate, seismic stress, seismic stiffness, seismic Deborah number and seismic Schmidt number. Select the non-seismic parameters to be analysed. Since the removal of rock at depth is the driving force of mine seismicity, seismic activity is closely correlated with mining production. Thus it is desirable to take the face advance into account when analysing the seismicity data (Van Aswegen, 2005). Only a few mines currently attempt to use face advance information in their daily analysis, 
citing difficulties in obtaining production data and transcribing it into a format that is compatible with the seismic monitoring system. This is an area for improvement in practice.

- Identify signals that might indicate a change in seismic hazard. The principles of the timely detection of rock mass instabilities implemented by ISSI are described in detail elsewhere (Mendecki et al., 1996; Mendecki, 1997). G. van Aswegen (ISSI, pers. comm., 2007) comments that the short-term seismic hazard assessment procedures have not changed significantly since 1995, the success rates are variable, and in some cases the seismic rock mass response to mining is too fast or too slow for the methods to be useful on a daily basis.

- Quantify the SHA success rate. The success of an SHA method can only be determined if the objective of this method has been clearly stated, which had not been done by most of the mines that were surveyed. In most cases, the objectives for short- and medium-term SHA were defined in broad terms, e.g. "to raise awareness", "to check on ground conditions and compliance with support standards", or "to select areas for subsequent visits by safety, production or rock engineering personnel”.

- React to a warning. Various reaction procedures have emerged during the past few years. On many mines, there is a requirement that an audit should be conducted prior to the crew entering of any working place that has been identified as having a high rockburst risk. The audit should be conducted by a senior official (e.g. mine overseer) or rock engineering practitioner. The purpose of the audit is to ensure that support and escape ways meet standards. The support may be augmented if poor ground conditions are identified. The crew may be prevented from entering the working place until the rockburst risk has subsided. However, this practice is considered problematic by some practitioners as blasting, which could trigger seismicity and release the stresses, is postponed. There is currently no proven method to define a safe re-entry time following a warning.

\subsection{Back analysis}

Back analyses should be carried out in the case of any seismic event or series of events that were exceptionally large or in unusual locations, or any rockburst that has caused injury, significant damage or loss of production. Back analyses are performed in an effort to understand the immediate and contributory causes of the seismic event and/or rockburst, so that measures may be taken to mitigate the risk and prevent recurrence in the future.

\section{Rockburst risk management}

The report of the Tripartite Working Group on Risk Assessment (SIMRAC, 1995) provides practical guidelines on how to perform risk assessments that will meet the requirements of the Mine Health and Safety Act (Act 29 of 1996). The report notes, "there are no fixed rules about how the risk assessment process should take place. The assessment carried out will very much depend on the nature of the work and the type and the extent of the hazard and risks".

It was the intention of this study to record current rockburst risk management practice and experience, and to formulate guidelines and standards so that the risk would be managed more effectively in the future. The survey of practice on mines revealed that a variety of rockburst risk management systems are in use. The systems are in the process of development, and the effectiveness of the various systems has not been rigorously evaluated. It was concluded that it is premature to define standards or even to formulate guidelines. It is recommended that the South African mining community subject their rockburst risk management systems to rigorous scrutiny and share the findings to the benefit of all.

The finding that rockburst risk management practice is immature does not necessarily mean that South African practice is lagging behind the rest of the world. In fact, South African rock engineering practitioners are providing some of the leading thinking on the topic. At the recent Third International Symposium on Deep and High Stress Mining (Quebec City, 2-4 October 2006), four of the eight papers that dealt explicitly with risk management issues were by South African authors (Durrheim et al., 2006; Joughin et al., 2006, Pretorius, 2006; Stacey et al., 2006). 


\subsection{Ethical issues}

There is often a fundamental difference between civil and mining engineering projects (Stacey et al., 2006). The design requirements for a civil engineering project (e.g. a road tunnel or dam) are usually clearly defined, and usually require a conservative design as the projects are usually of a long-term nature and are open to the public. In contrast, many mining excavations are temporary or short term, not open to the public, and the viability of a project is usually critically sensitive to costs.

Risks are an integral part of mining. The risks include the risk of injury or death, damage to equipment, loss of production, loss of reputation, failure to fulfil contractual obligations, and industrial action. The risk of a fatality occurring is probably the most sensitive risk faced by mining companies. While most companies proclaim a "zero tolerance" approach, Stacey et al. (2006) state that this an unrealistic approach, and argue for an approach that uses comparative fatality statistics to define a level of acceptable risk.

The level of risk that is regarded "acceptable" is a necessary and significant consideration in any mining project or operation and is inextricably linked to ethics. This requires input from executive management. Corporate strategies should stipulate the levels of risk that are acceptable to the mining company, and this will form the basis of the criteria for all mine design and operational activities. The same can be said for the environmental (e.g. dust and heat) and health risks associated with mining.

\subsection{Rockburst risk management systems}

The survey of current practice on South African mines revealed a range of rockburst management systems, which have been formalised to greater and lesser extent. Pretorius (2005) describes a credible, defensible and transparent risk management system that could be applied to various aspects of a mining operation, from the risk of injury to personnel, the loss of critical excavation(s) or equipment, to the financial loss due to the failure of a project. Pretorius (2006) presents two case studies that demonstrate the application of the above methodology to the rock-related hazards of deep mining. Bosman and Visser (2001) describe a system to manage seismic risk at Hartebeesfontein Gold Mine. Joughin et al. (2006) describe a methodology for determining seismic risk associated with regional pillars at South Deep Gold Mine. AngloGold Ashanti introduced a five-point Fall of Ground Management system, known as FOGM, in 2002 (Trevarthen, 2006). The strategy focuses on mine design, mine support standards, mindset, monitoring and research. The operational pillars of the strategy were rolled out over five years. Strategies to manage seismicity in a deep Ventersdorp Contact reef environment at Mponeng Mine are described by McGill (2005).

\section{Seismic scorecard}

The balanced scorecard, a concept for measuring a company's activities in terms of its vision and strategies, was introduced in the early 1990s. The key new element was the focus on the human issues that drive the financial outcomes, to enable organisations to focus on the future and act in their long-term best interest (http://en.wikipedia.org/wiki/Balanced_Scorecard, 2007). Implementation of a scorecard typically includes four processes:

1. Translating the vision into operational goals.

2. Communicating the vision and linking it to individual performance.

3. Business planning.

4. Getting feedback and learning and adjusting the strategy accordingly.

Since the original concept was introduced, balanced scorecards have become a fertile field of theory and research, and many practitioners have adapted the original concept to other fields of endeavour. We have attempted to develop a "seismic scorecard", a tool intended to assist a rockburst-prone mine to continuously improve its system to manage rockburst risk. The main elements of the scorecard are described in Table 3. The overall score should be a reflection of a mine's efforts to optimise the design and operation of its seismic network. A high score will reflect the considerable effort a mine will have made to accurately quantify the seismic hazard level in various parts of its operation, thereby reducing the risk and complying with legal requirements. 
Table 3 Elements of a Seismic Scorecard

System design according to monitoring objectives

$30 \%$

Mine subdivided into zones of varying seismic hazard

Monitoring objectives defined per hazard district

Monitoring objectives translated into required network performance

Network design according to desired performance (within constraints of access)

Network installed according to design

Calibration blasts carried out for velocity model and location accuracy

Motivation and design process documented

Seismic system operation and data collection

Station days lost below $20 \%$ for past year, no deterioration over time

$80 \%$ of sensors fully functional (stable over time)

Adequate resources for system maintenance and upgrade

Seismic raw data are quality controlled

Minimum of 5 stations per event, 8 picks, 8 spectra

Data back-up procedures in place

Magnitude relation adjusted to CGS catalogue; time base calibrated

System operation and maintenance procedures documented

Annual review performed (internal or external)

Seismic data analysis procedures

$30 \%$

Emergency event location

Back-analysis of large events

Short-term seismic hazard procedure(s) - description and evaluation

Medium-term seismic hazard procedure(s) - description and evaluation

Long-term seismic hazard procedure(s) - description and evaluation

Exchange of information with other disciplines (rock engineering, geology, safety, production)

Needs of recipients of seismic information assessed

Written procedures for communication, roles and responsibilities

Performance of methods assessed, improvements planned and implemented

External review of procedures every two to three years, with the findings documented and evidence that the recommendations were implemented

\section{Conclusions}

Rockbursts are a major risk of deep and high-stress mining in South Africa, causing damage to infrastructure, loss of production, and injury and death to mine workers. Mine owners and managers are required by law to take "reasonable measures" to ensure that the working environment is healthy and safe when a mine is designed, constructed, equipped, operated and decommissioned. Seismic monitoring, analysis and interpretation are key components of the risk management system on rockburst-prone mines.

Monitoring has been taking place on a routine basis in South African mines for nearly three decades, and seismic monitoring systems are now operational on virtually all rockburst-prone mines in South Africa. During this time there have been major improvements in data capture and processing as a result of advances in electronics and computing. During the last decade there have been significant changes in the way the seismic service is provided, as many mining companies have chosen to outsource some or all parts of the operation. Many mines have changed hands in the last decade, which has sometimes led to gaps in 
monitoring and loss of databases. New data processing and seismic hazard assessment procedures were introduced in the mid-1990s, but there has not been significant change since then.

It has been possible to set standards for some areas of mine seismology practice such as network design and emergency response. In other areas of practice, such as data processing, it has only been possible to provide guidelines. In yet other areas of practice, such as seismic hazard assessment and risk management, most methods currently in use have not been rigorously evaluated and validated. Many methods rely, to a greater or lesser extent, on local experience and subjective judgement. Tacit knowledge still has to be translated into explicit guidelines and standard procedures. Thus it is deemed premature to set standards, or even firm guidelines.

Long- and medium-term seismic hazard assessments are widely used when designing mine layouts and sequences. However, there is unanimous agreement that the short-term SHA is not reliable enough to be used for routine rockburst risk management, despite considerable research effort. Although this has proven to be a difficult and perhaps intractable problem, it is believed to be worthwhile to persevere with efforts to improve SHA procedures. There are several promising avenues of research. For example, the forecasting of rockbursts might be improved through real-time integration of seismic and rock deformation data (ranging from acoustic emissions to measurements of stope closure and tilt), mining data, and numerical models of rock mass behaviour.

\section{Acknowledgements}

The Mine Health and Safety Council is thanked for sponsoring the project and for permission to present the findings. Many people and organisations participated in this study, and their contributions are gratefully acknowledged. They include Dr Gerrie van Aswegen of ISSI, and the interviewees at Bambanani, Elandsrand, Great Noligwa, Impala, Kloof, Mponeng, Rustenburg Section of Anglo Platinum, Savuka, South Deep and TauTona mines.

\section{References}

Bosman, J.D. and Visser, A.V. (2001) A process of managing the seismic risk at Hartebeestfontein GM. Proceedings $5^{\text {th }}$ International Symposium on Rockbursts and Seismicity in Mines, G. van Aswegen, R.J. Durrheim and W.D. Ortlepp (eds), The South African Institute of Mining and Metallurgy, Symposium Series S27, pp. 515-519.

Brune, J.N. (1970) Tectonic stress and the spectra of seismic shear waves from earthquakes. J. Geophys. Res., 75, pp. 4997-5009.

Cichowicz, A., Spottiswoode, S.M., Linzer, L.M., Drent, D., Heyns, P.S. and Handley, M.F. (2005) Improved seismic locations and location techniques, final report for MHSC project SIM 02-03-04.

DME (2002) Guideline for the compilation of a mandatory Code of Practice to combat Rock Fall and Rock Burst Accidents in Tabular Metalliferous Mines, DME 16/3/2/1-A3 (Revision 1 February 2002), Department of Minerals and Energy.

Durrheim, R.J. (1999) Rockbursting. In A Handbook on Rock Engineering Practice for Tabular Hard Rock Mines, A.J. Jager and J.A. Ryder (eds), Chapter 8, pp. 249-285, SIMRAC, Johannesburg.

Durrheim, R.J., Cichowicz, A., Ebrahim-Trollope, R., Essrich, F., Goldbach, O., Linzer, L.M., Spottiswoode, S.M. and Stankiewicz, T. (2007) Guidelines, Standards and Best Practice for Seismic Hazard Assessment and Rockburst Risk Management, Final Report, project SIM 05-03-02 (Phase 2, Output 3), South African Mine Health and Safety Council.

Durrheim, R.J., Anderson, R.L., Cichowicz, A., Ebrahim-Trollope, R., Hubert, G., Kijko, A., McGarr, A., Ortlepp, W.D. and Van der Merwe, N. (2006) The Risks to Miners, Mines, and the Public posed by Large Seismic Events in the Gold Mining Districts of South Africa. Proceedings $3^{\text {rd }}$ International Seminar on Deep and High Stress Mining, J. Hadjigeorgiou and M. Grenon (eds), Université Laval, Canada, Section 30.

Jager, A.J. and Ryder, J.A. (editors) (1999) A handbook on rock engineering practice for tabular hard rock mines, Safety in Mines Research Advisory Committee, Johannesburg, 369 p.

Joughin, W.C., Thompson, J.J. and Pethö, S.Z. (2006) South Deep Gold Mine Regional Pillar Modelling Part III towards a methodology for determining seismic risk associated with deep tabular mining. Proceedings $3^{\text {rd }}$ International Seminar on Deep and High Stress Mining, J. Hadjigeorgiou and M. Grenon (eds), Université Laval, Canada, Section 23.

McGill, R. (2005) Strategies to manage seismicity in a deep VCR environment at Mponeng, Proceedings $6^{\text {th }}$ International Symposium on Rockbursts and Seismicity in Mines, Y. Potvin and M. Hudyma (eds), Australian Centre for Geomechanics, pp. 419-424. 
Mendecki, A.J. (editor) (1997) Seismic monitoring in mines, Chapman and Hall, London, 262 pp.

Mendecki, A.J., Brink, A. van Z., Green, R.W.E., Mountfort, P., Dzhafarov, A., Niewiadomski, J., Kijko, A., Sciocatti, M., Radu, S., Van Aswegen, G., Hewlett, P., De Kock, E. and Stankiewicz, T. (1996) Seismology for rockburst prevention, control and prediction. SIMRAC Final project report, GAP 017, Department of Minerals and Energy, South Africa.

Mendecki, A.J., Van Aswegen, G. and Mountfort, P. (1999) Guide to Routine Seismic Monitoring in Mines. In A Handbook on Rock Engineering Practice for Tabular Hard Rock Mines, A.J. Jager and J.A. Ryder (eds), Chapter 9, pp. 287-309, SIMRAC, Johannesburg.

Pretorius, M.J. (2005) Managing the risk once the risk profile has been established. Proceedings $3^{\text {rd }}$ Southern African Rock Engineering Symposium (SARES2005), SAIMM Symposium Series S41, pp. 335-343.

Pretorius, M.J. (2006) Quantification and management of risk in a deep mining environment - Harmony Gold Mining Co. Ltd approach. Proceedings $3^{\text {rd }}$ International Seminar on Deep and High Stress Mining, J. Hadjigeorgiou and M. Grenon (eds), Université Laval, Canada, Section 26.

SIMRAC (1995) Practical Guide to the Risk Assessment Process. Final Report, GAP 225, Mine Health and Safety Council, Johannesburg.

Spottiswoode, S.M. (2005) Mine layout design and medium-term prediction of seismicity. Proceedings $6^{\text {th }}$ International Symposium on Rockbursts and Seismicity in Mines, Y. Potvin and M. Hudyma (eds), Australian Centre for Geomechanics, pp. 211-217.

Spottiswoode, S.M. and Linzer, L.M. (2005) A Hybrid Location Methodology, Journal South African Institute Mining Metallurgy, Vol. 105, pp. 417-426.

Spottiswoode, S.M., Scheepers, J. and Ledwaba, L. (2006) Pillar seismicity in the Bushveld Complex. Proceedings SANIRE 2006 Symposium, South African National Institute of Rock Engineering, pp. 140-158.

Spottiswoode, S.M., Milev, A., Linzer, L.M. and Majiet, S. (2007) Evaluation of the design criteria of Regularly Spaced Dip Pillars (RSDP) based on their in-situ performance, SIM-04-03-01 final report (in preparation).

Stacey, T.R., Terbrugge, P.J. and Wesseloo, J. (2006) Risk as a rock engineering design criterion. Proceedings $3^{\text {rd }}$ International Seminar on Deep and High Stress Mining, J. Hadjigeorgiou and M. Grenon (eds), Université Laval, Canada, Section 27.

Trevarthen, N. (2006) A strategy to manage falls of ground and rockbursts (abstract). Proceedings International Mining and Metals Safety and Health Conference 2006, 14-16 November 2006, Johannesburg, South Africa, International Council on Mining and Metals, 51 p.

Trifu, C-I. (2001) Assessing the rock mass condition by the analysis of failure mechanisms. Proceedings $5^{\text {th }}$ International Symposium on Rockbursts and Seismicity in Mines, G. van Aswegen, R.J. Durrheim and W.D. Ortlepp (eds), The South African Institute of Mining and Metallurgy, Symposium Series S27, pp. 75-80.

Van Aswegen, G. (2003) Applications of seismic hazard assessment methods in mines. Proceedings $10^{\text {th }}$ Congress of the ISRM, The South African Institute of Mining and Metallurgy, Symposium Series S33, pp. 1261-1268.

Van Aswegen, G. (2005) Routine seismic hazard assessment in some South African mines. Proceedings $6^{\text {th }}$ International Symposium on Rockbursts and Seismicity in Mines, Y. Potvin and M. Hudyma (eds), Australian Centre for Geomechanics, pp. 437-444. 